\author{
Military Technical College \\ Kobry El-Kobbah, \\ Cairo, Egypt
}

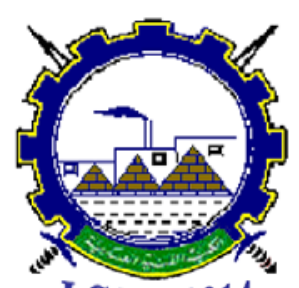

I.C.E.E.2014 $7^{\text {th }}$ International Conference

on

Chemical \& Environmental

Engineering

27 - 29 May, 2014.

\title{
Stability of double base propellants, a comparison between classical stability tests and modern analytical techniques
}

\author{
A.Abdelgawad ${ }^{*}$, M.Elshaher ${ }^{\dagger}$, and H.E. Mostafa*
}

\begin{abstract}
:
Shelf life of weapons becomes a very important issue and due to the increasing number of "out-of-area" missions also for the nations in the moderate climatic regions. The shelf life is often limited by propellant ageing. Double base Propellants undergo slow chemical decomposition reactions already at room temperature and even more at elevated temperatures. Six different samples of double base propellants were investigated through classical stability tests (Abel test, Bergmann-Junk test, high performance liquid chromatography) and modernized vacuum stability test (SABIL).

The results of the propellants life-time predictions obtained in accordance with STANAG 4556 methodology by the expression for the amount of gases evolved from samples, in addition of the safe life determination were consistent.
\end{abstract}

Keywords: Shelf life, double base propellants and Vacuum stability test.

\footnotetext{
Egyptian Armed Forces

† British University, Cairo, Egypt
} 


\section{Introduction}

Propellants are energy-rich substances capable of releasing their energy after initiation at a high rate. Generally, energy rich substances are thermodynamically unstable. Consequently they undergo slow chemical decomposition reactions. This process involves numerous chemical decomposition mechanisms such as chain mechanism, autocatalytic mechanism and thermal mechanism [1].

As a consequence, stability of propellants have to be thoroughly investigated before propellants can be safely manufactured, stored and used in technical applications. Numerous stability test procedures for propellants in military applications are described in several standards, the most important being STANAG (Standardization Agreement of NATO, which contains all tests used in NATO countries during explosive qualification), AOP-7 (Allied Ordnance Publication, , MIL-STD (Military Standards, USA), DEF STAN (Defense Standards, GB), TL (Technische Lieferbedingungen, Germany), etc. [2].

Total life cycle of weapon system can be defined as shelf life. Shelf life is the period of time (beginning from the date of manufacture) that an item can remain in its hermetically sealed container and still be serviceable. (= safe life + service life) [3].

This work mainly focuses on the difference between results of classical stability tests and modern analytical technique.

\section{Experimental}

Tested materials were samples of extruded double base rocket propellants from different lots for the same application (PJ-7). The studies were performed on double base rocket propellant samples of chemical composition, shown in Table.

Table (1). The composition of tested samples

\begin{tabular}{|c|c|c|}
\hline Component & (wt \%) & Function \\
\hline NG & 30.2 & Energetic plasticizer \\
\hline NC $(12.1 \% \mathrm{~N})$ & 57.8 & Energetic polymer \\
\hline Dibutylphathalate & 5 & Inert plasticizer \\
\hline Centralite I & 3 & Stabilizer \\
\hline Lead stearate & 1.9 & Ballistic modifier \\
\hline Carbon black & 0.2 & Opacifier \\
\hline Dinitrotoluene & 1.9 & Energetic plasticizer \\
\hline
\end{tabular}




\subsection{Classical stability tests}

The classical stability tests conducted for these samples are:

- Soxhlet extraction then analysis of the residual concentration of stabilisers and derivatives by liquid chromatography (HPLC).

- $\quad$ Abel heat test $\left(80{ }^{0} \mathrm{C}\right)$.

- Bergmann - Junk test $\left(120{ }^{0} \mathrm{C}\right)$.

- The ignition temperature was also determined.

\subsubsection{Abel heat test $\left(80^{\circ} \mathrm{C}\right)$}

\section{- Principle of the test}

It is based on the determination of the time needed for the split of nitrogen oxides to produce yellow -brown to blue violet color of potassium iodide starch paper. The essence is the separation of iodine according to the reaction.

$$
2 \mathrm{KI}+\mathrm{NO}_{2}+\mathrm{H}_{2} \mathrm{O} \longrightarrow 2 \mathrm{KOH}+\mathrm{NO}+\mathrm{I}_{2}
$$

\section{- Apparatus used}

1) Metallic boiler filled with mixture of glycerin and $\mathrm{H}_{2} \mathrm{O}$ or with transformer oil.

2) It is equipped with level indicator to enable check of liquid level.

3) It is electrically by means of contact thermometer.

4) For the contact thermometer a shortened open tube is provided for the thermometer to be directly in the oil.

5) Into one tube a test tube with a precision control thermometer is introduced.

6) Glass test tubes plugged with a rubber stopper a hook is provided, fixed on the hook are potassium iodide starch papers.

7) The test tubes are inserted in the metallic tubes of the boiler.

\section{- Procedure}

1) A charge $1 \mathrm{~g}$ is weighed and put in a test tube which is sealed with rubber stopper provided with a stick on whose end a potassium iodide starch paper is suspended.

2) In its upper third the paper is wetted with water glycerin mixture (1:1) in a band 3-4 mm wide.

3) The time elapsed from the insertion into test tubes till the paper is colored is expressed in minutes, determine the chemical stability at $80{ }^{\circ} \mathrm{C}$.

4) Measure the time needed to change color of KI starch paper.

\subsubsection{Bergmann-Junk Test}

\section{- Principle of the test}

Dried powder is exposed to at $120 \pm 0.5^{\circ} \mathrm{C}$ in glass tubes, the decomposition products are absorbed in water and quantitavely determined using common methods, the result is expressed in $\mathrm{ml}$ of $\mathrm{NO}$ formed by the decomposition of $5 \mathrm{gm}$ of powder. 


\section{- Procedure}

1) The powder is dried for 5 hrs at $100 \pm 1{ }^{\circ} \mathrm{C}$.

2) A charge of $5 \pm 0.01$ of so dried powder is weighed into a test tube.

3) With each powder tow parallel determinations and one blind test are carried out.

4) Once the test powder has been poured into the test tubes the ball extension are put on and using pipette $50 \mathrm{ml}$ of distilled water are measured.

5) Prepared test tubes are introduced into the boiler heated to $120 \pm 0.5^{\circ} \mathrm{C}$.

6) Ten minutes later, the extensions are sealed with plugs.

7) Then by convenient turning and shaking of the test tubes water is transferred from the extension into the test tubes and back.

8) The plug is removed from the extension.

9) The liquid is poured through a funnel with a quantitative filter into backer of $400 \mathrm{ml}$ capacity.

10) With out separation extension from the tube, the remain in both is washed with $50 \mathrm{ml}$ distilled water and poured into the funnel 3 times

11) The final volume of the liquid $200 \mathrm{ml}$.

12) During last filtration powder is transferred from the tube on a filter, here it is washed using $25 \mathrm{ml}$ of distilled water.

13) Excess $(10 \mathrm{ml})$ of $0.1 \mathrm{~N} \mathrm{NaOH}$ has been put per each assumed $20 \mathrm{ml}$ of $\mathrm{NO}$ from 5 gm of powder.

14) The obtained solution is titrated with $0.1 \mathrm{~N} \mathrm{HCl}$ a against methyl red to a clear pink color.

15) Calculating number of $\mathrm{ml}$ of NO liberated by thermal decomposition of $5 \mathrm{gm}$ of powder [4].

\subsubsection{Determination of ignition temperature}

\section{- Principle of the method}

The ignition temperature can be experimentally determined by heating a sample of a given mass at a constant rate of temperature increase until the ignition occurs. The ignition temperature test can be performed in the deflagration test apparatus.

\section{- Apparatus components}

1) An Aluminum heating block comprising three holes to accommodate (16 mm x 125 $\mathrm{mm}$ ) test tubes heated electrically.

2) A eurotherm temperature control box (as a programmable heating controller), allowing the heating block to be controlled remotely; that monitors temperature up to accurately of $\pm 0.10^{\circ} \mathrm{C}$.

3) A heat sink and fan to accelerate cooling down of the aluminum heating block.

\section{- Procedure of the test}

1) Carry $0.1 \mathrm{~g}$ of a sample that was previously dried up and ground to a suitable particle size and fill each of the 3 test tubes with it.

2) Insert the 3 test tubes into the heating block.

3) Switch on the eurotherm temperature control box with the front panel.

4) Set the set-point temperature to the desired set-point (which is $400{ }^{\circ} \mathrm{C}$ by default). 
5) Set the ramp rate to the desired set-point $\left[20^{\circ} \mathrm{C} / \mathrm{min}\right]$.

6) Press the eurotherm control box RED reset button.

7) The heating block will start to heat up at the operators requested ramp rate [20 $\left.{ }^{\circ} \mathrm{C} / \mathrm{min}\right]$.

8) Watch the test tubes until defloration of the explosive occurs.

9) The temperature will increase until it reaches the operator set-point where the heating block will remain at this temperature $\left[400^{\circ} \mathrm{C}\right]$.

10) Switch off the device after reaching the defloration temperature and cool down the heating block by using the fanned heat sink [5].

\section{- Evaluation of results}

Record the ignition temperature of the three samples in the three test tubes where the ignition temperature is determined as the lowest temperature of the three parallel test samples.

\subsection{Applications of HPLC}

Put $10 \mathrm{gm}$ of powder in the middle part of extractor in Soxlet extraction. Extraction flask filled with ether fix the middle part to the ground joint and connect the condenser allow ether to evaporate.

As other chromatographic methods HPLC can be employed not only for separation but also for identification, by comparing the retention time of the unknown compound to that of a known one (standard) under the same operating conditions. HPLC technique can be used as qualitative and quantitative method of identification of explosives through retention time and Peak area respectively. The most common detector in HPLC is a UV spectrophotometer, whose detection is based on the fact that many organic compounds absorb in the UV region while many eluents are transparent this region. The application of this technique in detection and identification of most commonly stabilizers used in double base propellants.

\section{- Instrumentation}

The applied instrument in this work for propellants investigation was Agilent 8100 HPLC instrument. The main constituent of the instrument are:

(1) Quaternary pump which operate with four eluents at controlled ratio and flow rate.

(2) Degassing unit.

(3) Auto sampler.

(4) Stationary phase: Controlled temperature reversed phase column.

(5) UV-Visible detector.

All common instrument control analysis and reporting tasks were performed automatically. All data processing can be automated and included as part of a method, by the aid of HP3D LC Chemistation software.

\section{- Operating conditions}

Stationary phase: $150 \mathrm{~mm} * 10 \mathrm{~mm}$ Id reversed phase column Zorbax SB C-18.

Mobile Phase: Acn -Water - methanol.

Flow rate: $1.5 \mathrm{ml} / \mathrm{min}$.

Injection volume: $3 \mu 1$.

Detector: UV Detector at $230 \mathrm{~nm}$.

Post run: 10 minute. 
Column temperature: $28{ }^{\circ} \mathrm{C}[6]$.

Table (2). The results of ignition temperature and classical stability tests for tested samples.

\begin{tabular}{|c|c|c|c|c|}
\hline Sample & $\begin{array}{c}\text { Stabilizer Content } \\
\text { (wt \%) }\end{array}$ & $\begin{array}{c}\text { Ign. temp. } \\
\mathbf{( { } ^ { \mathbf { 0 } } \mathbf { C } )}\end{array}$ & $\begin{array}{c}\text { Abel test } \\
\text { (min) }\end{array}$ & $\begin{array}{c}\text { B-J } \\
\text { (ml NO / 5 g) }\end{array}$ \\
\hline D-1 & 3 & 191 & 30 & 4.4 \\
\hline D-2 & 2.81 & 192 & 25 & 5.4 \\
\hline D-3 & 2.8 & 185 & 25 & 5.2 \\
\hline D-4 & 2.75 & 186 & 25 & 5.4 \\
\hline D-5 & 2.75 & 193 & 25 & 5.4 \\
\hline D-6 & 2.70 & 189 & 20 & 6.0 \\
\hline
\end{tabular}

It was found that there is no significant difference in ignition temperatures, varying from 185 to 193, Table (2). The stabilizer content effect on chemical stability is clear from the results of Abel test and Bergmann-Junk test. These results are accepted for double base propellants but the remaining safe life of these samples cannot be predicted.

\subsection{Modern techniques of stability}

Typically, these tests determine whether the shelf life is shorter or longer than 10 years at 25 ${ }^{\circ} \mathrm{C}$. As test time and cost are moderate, this test type is mostly used during explosive qualification and only rarely applied for quality control of produced lots and for storage surveillance.

\subsubsection{Modernized vacuum stability test (STABIL)}

STABIL is a controlling, measuring and evaluating system, enabling evaluation of temperature stability from measurements of the volume of gas evolved from a sample during long term isothermal heating. It provides objective results from the entire process of stability evaluation and may be performed in vacuum, with presence of gasses (inert-nitrogen, oxidative - oxygen) or under air at atmospheric pressure at the beginning of the test.

It permits a completely automated determination of chemical stability of smokeless powders, explosives, nitrocellulose, raw materials, mixtures and material substances which are decomposed during a long term temperature treatment under generated gas products [7].

\section{- Sample preparation}

The weighed amount of sample (1g) is inserted into a test tube. The sample should be solid or powdery. It is recommended to use a glass funnel for filling when appropriate to avoid contamination of the test tube wall by the sample.

\section{- Evacuating test tubes}

Once you have all the samples prepared. Insert a $4 \mathrm{~mm}$ hose to the test tube fitting, open the appropriate valve of the vacuum manifold and turn on the vacuum pump.

Let the vacuum pump running until pressure in the apparatus drops down beneath the desire value, e.g. $500 \mathrm{~Pa}$. The actual value is shown on the computer screen however it is necessary 
to have Winstab Test Site panel active. Then close the apparatus by twisting the transducer either clock-wise or counter clock-wise for 180 degree. The apparatus is now ready for measurement.

\section{- Measurement}

Now, when all the test tubes are ready, the measurement can be run. Choose the appropriate measurement method using Winstab software and according to STANAG 4556 and MIL STD 1751A [9], (90 ${ }^{\circ} \mathrm{C}$ for $\left.40 \mathrm{hr}\right)$. The results are listed in table (3).

Table (3). The results of STABIL

\begin{tabular}{|c|c|c|}
\hline Sample & $\begin{array}{l}\text { Experimental result } \\
\left(\mathrm{cm}^{3} \text { of gases } / \mathrm{g}\right)\end{array}$ & $\begin{array}{l}\text { STANAG } 4556 \\
\left(\mathrm{~cm}^{3} \text { of gases /g) }\right.\end{array}$ \\
\hline D-1 & 1.580 & \multirow{6}{*}{$\begin{array}{c}\leq 7.99 \mathrm{~cm}^{3} \text { of gases } / \mathrm{g} \\
{[8] .}\end{array}$} \\
\hline D-2 & 1.981 & \\
\hline D-3 & 2.114 & \\
\hline D-4 & 1.744 & \\
\hline D-5 & 1.938 & \\
\hline D-6 & 2.145 & \\
\hline
\end{tabular}

From the above results, we can deduce that sample D-3 and D-6 are less sable that the rest of samples, and according to STANAG 4556 it was clear that all samples D-1 to D-6 are assessment $\geq 10$ years at $25^{\circ} \mathrm{C}$.

\section{Conclusions}

This paper investigated how the properties of the propellant would change during years in storage, with a specific interest in evaluating published methods of chemical stability analysis. The choice of methods depends exact on the substances under examination to some extent, on whether it is to be submitted to production or to acceptance testing.

For production testing, rapid methods are chosen whereas for acceptance tests accuracy and not time is decisive of the choice of method. At acceptance tests preference should also be given to methods allowing assessing the storage ability for normal conditions with a fair margin of safety. The Abel Heat Test, being quick and easy to execute, have therefore come into extensive use for production check-up.

The Bergmann \& Junk Test is an intermediate position since the test time totals approximately $5 \mathrm{hrs}$ and a reliable indication on the storage ability is obtained; thus, this test is used both in production and acceptance testing.

The results of the propellants life-times prediction obtained in accordance with STANAG 4556 methodology by the expression for the amount of gases evolved from samples gave an excellent result in addition of the safe life determination. 


\section{References}

[1] B. Vogelsanger, R. Sopranetti, B. Ossola, K. Ryf, Compatibility and Service Life Predictions of Propulsion/Ammunition Systems, 12th Symp. On Chemical Problems Connected with the Stability of Explosives, Karlsborg, Sweden, 2001.

[2] Beat Vogelsanger, "Chemical Stability, Compatibility and Shelf Life of Explosives ", Chimia 58 (2004).

[3] Beat Vogelsanger, Bruno Ossola, Ulrich Schädeli, Dominik Antenen and Kurt Ryf, "Ballistic shelf life of propellants for medium and small calibre ammunition influence of deterrent diffusion and nitrocellulose degradation ", $19^{\text {th }}$ International Symposium of Ballistics, 7-11 May 2001, Interlaken, Switzerland.

[4] AB Bofors, Nobelkrut, "Analytical Methods for Powders and Explosives” Bofers, 1974.

[5] Chilworth deflagration test apparatus catalogue, UK, 2003.

[6] James W. Robinson, Eileen M. Skelly Frame, George M. Frame, "Undergraduate Instrumental Analysis”, Sixth Edition, Marcel Dekker, 2005

[7] OZM Researsh, "Modernized Vacuum Stability Tester" User Manual, Czech Republic, September 2009.

[8] NORTH AGENCY TREATY ORGANIZATION, STANAG 4556, Edition 1, 1999. 